\title{
LA-UR-18-29893
}

Approved for public release; distribution is unlimited.

Title:

LANL Photo Collage

Author(s): $\quad$ Meade, Roger Allen

Intended for: $\quad$ General Orientation Talk for LANL Tours

Issued: 
Disclaimer:

Los Alamos National Laboratory, an affirmative action/equal opportunity employer, is operated by the Los Alamos National Security, LLC for the National Nuclear Security Administration of the U.S. Department of Energy under contract DE-AC52-06NA25396. By approving this article, the publisher recognizes that the U.S. Government retains nonexclusive, royalty-free license to publish or reproduce the published form of this contribution, or to allow others to do so, for U.S. Government purposes. Los Alamos National Laboratory requests that the publisher identify this article as work performed under the auspices of the U.S. Department of Energy. Los Alamos National Laboratory strongly supports academic freedom and a researcher's right to publish; as an institution, however, the Laboratory does not endorse the viewpoint of a publication or guarantee its technical correctness. 


\section{LANL PHOTO COLLAGE}

- The photographs in this presentation are intended as a general introduction to the Laboratory and its history. Particular attention is given to criticality experiments and measurements. The intended audience is for students and new hires into group C-NR. 


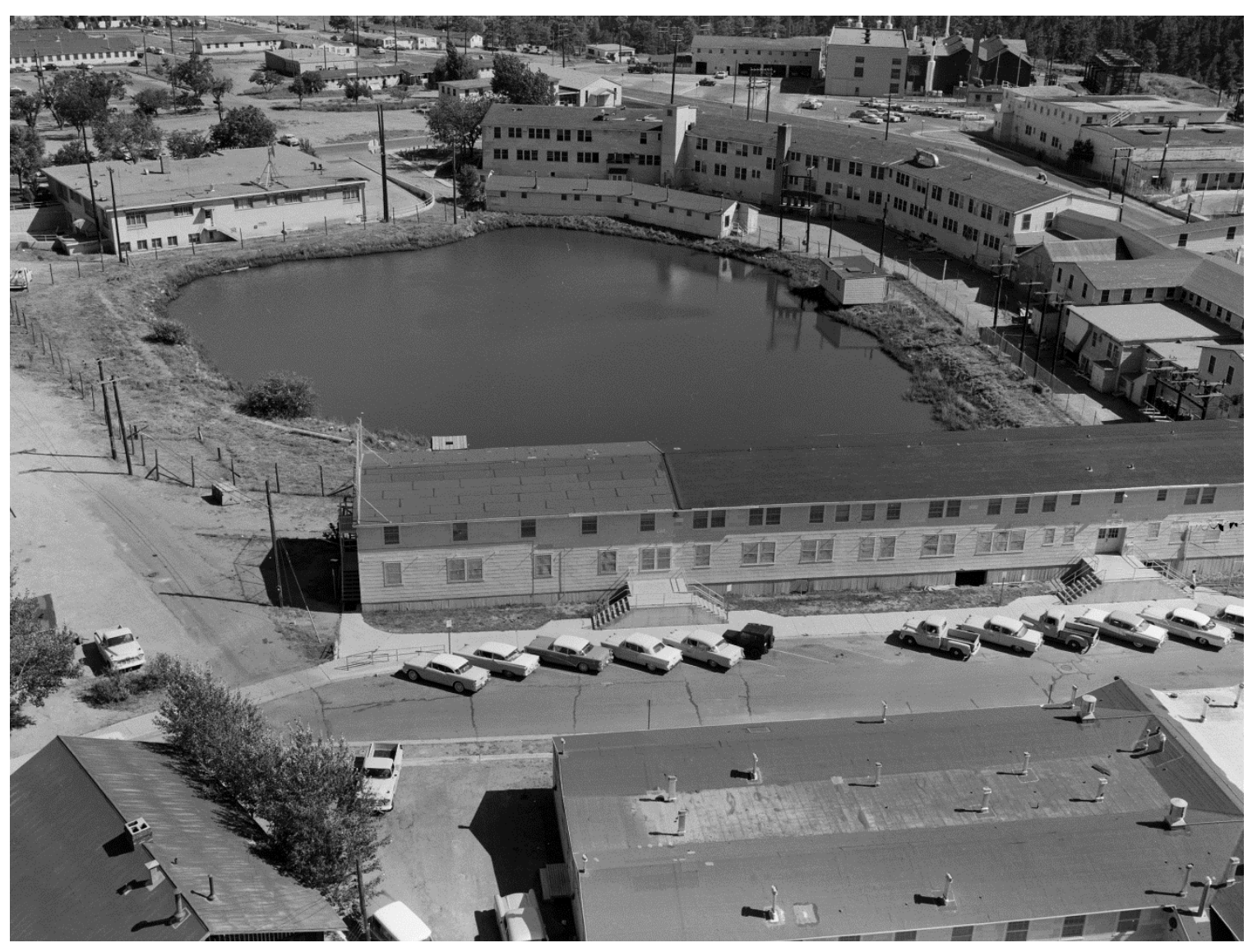

Main Technical Area - early 1950s 


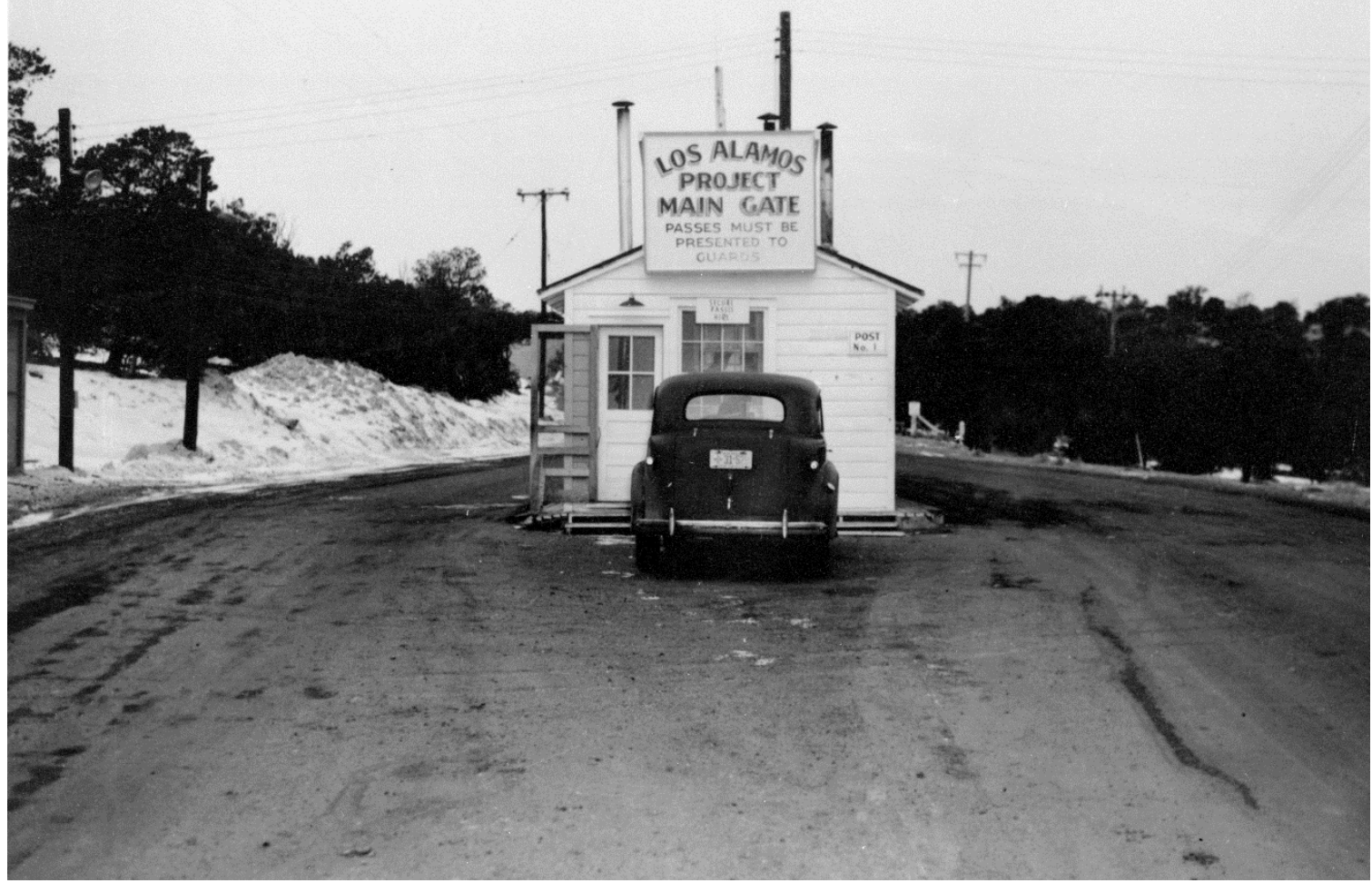

Main Gate - 1945 


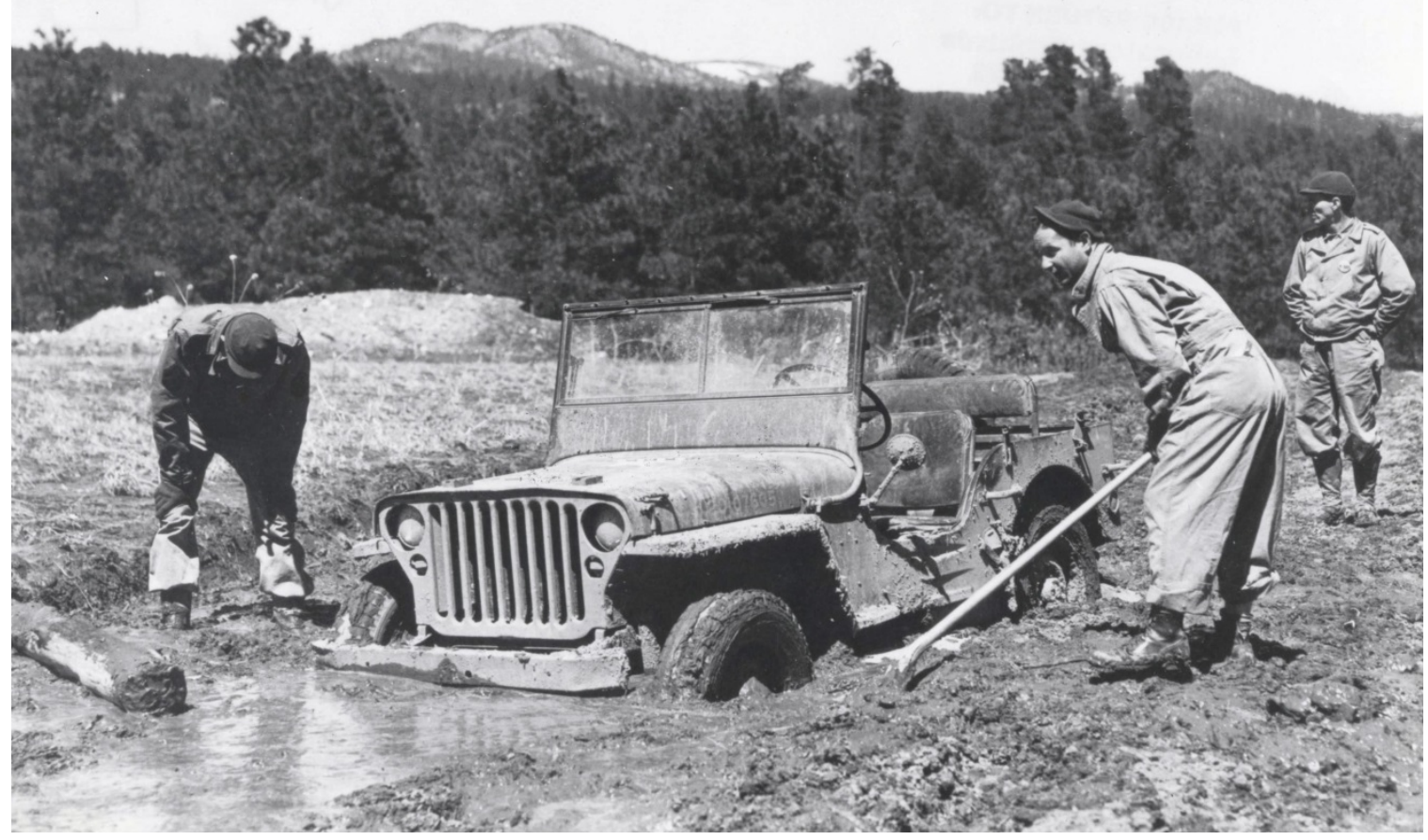

\section{Wartime Los Alamos}

Edward Teller: The most remarkable thing about Los Alamos was the absence of grass. 


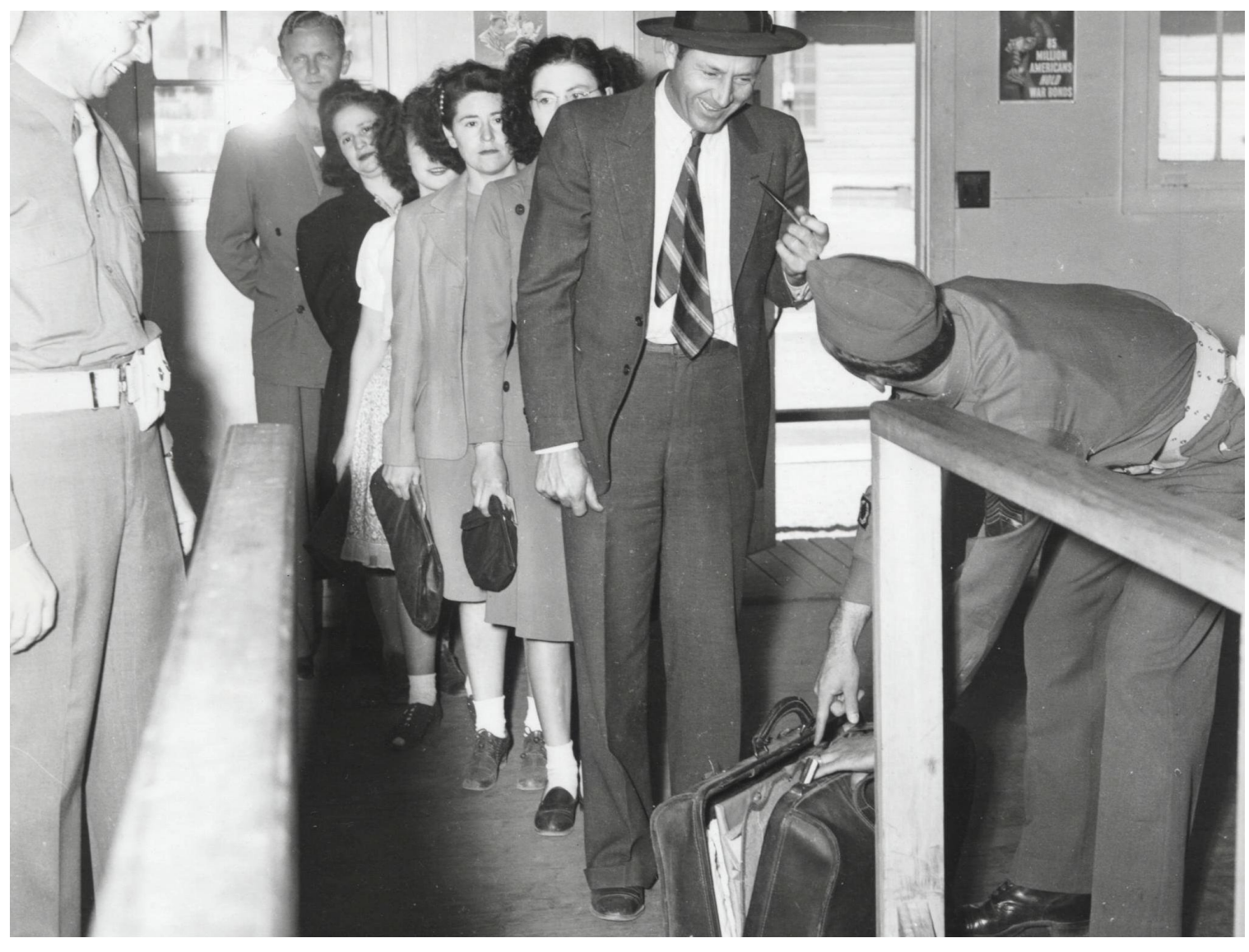

\section{Security Check 1946}

Essentially the same process today. 


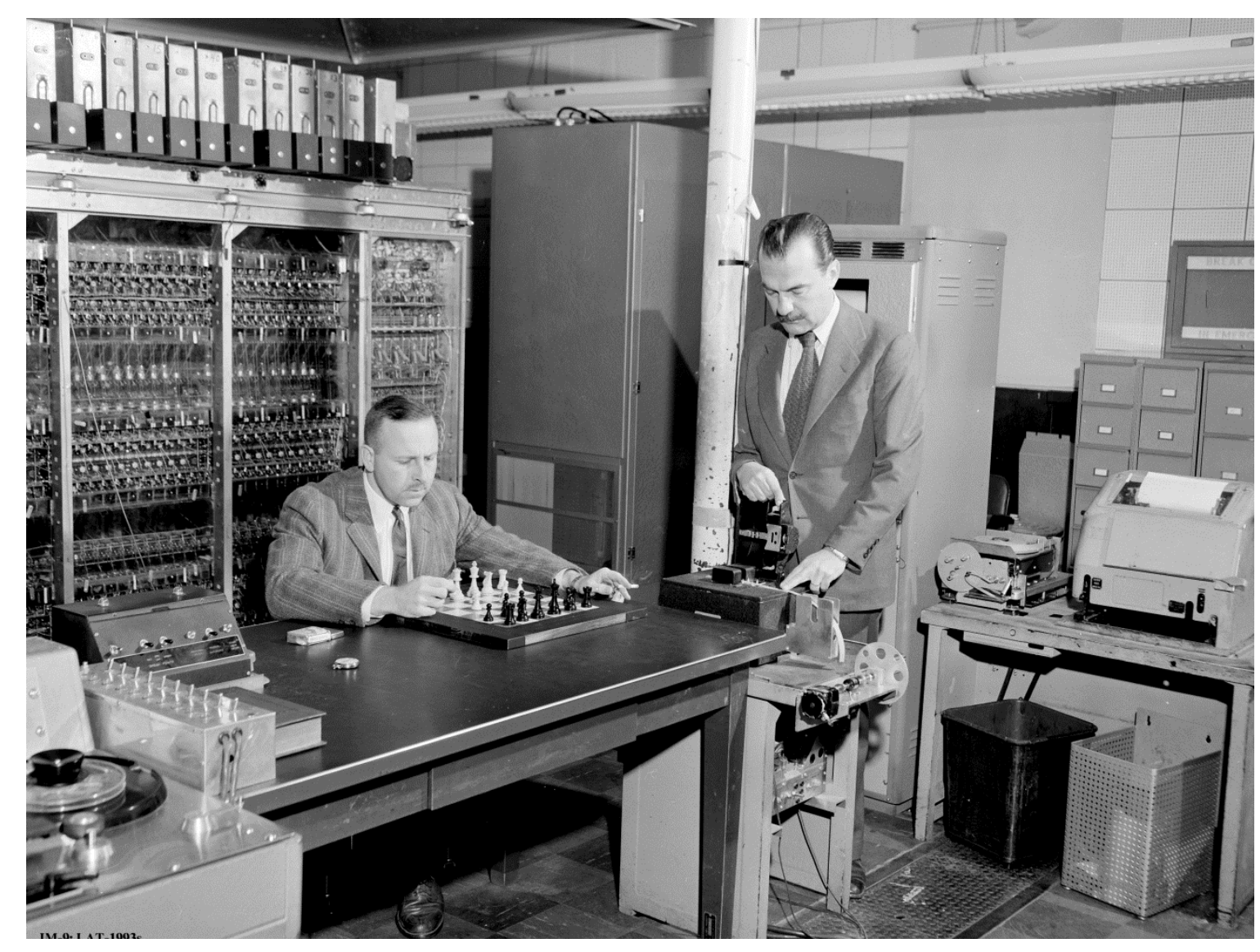

\section{Early Computer - playing chess}

Codename: "MANIAC" 


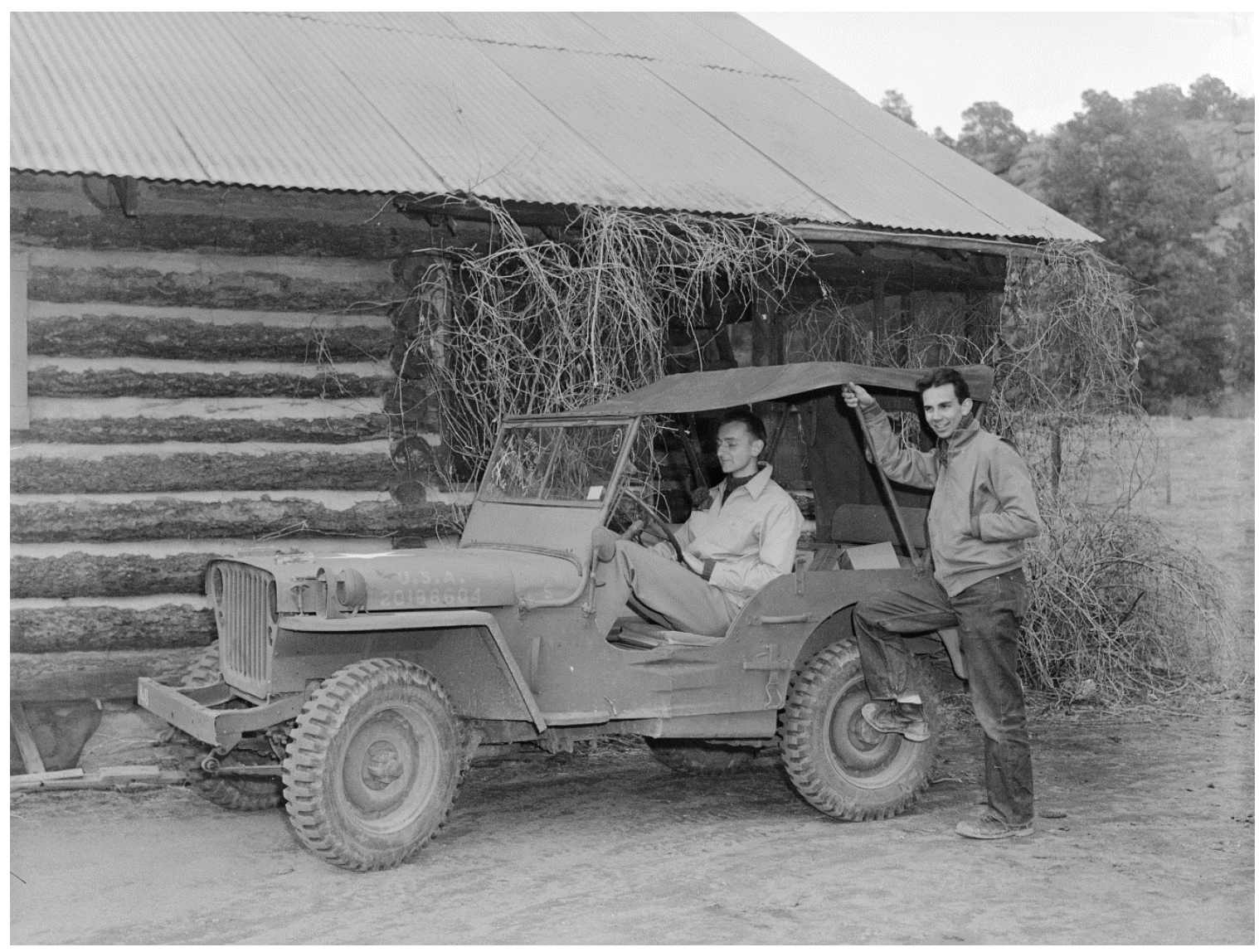

\section{TA-18 Cabin}

Cabin where future Nobel Laureate, Emilio Segre, and graduate students discovered spontaneous fission. 


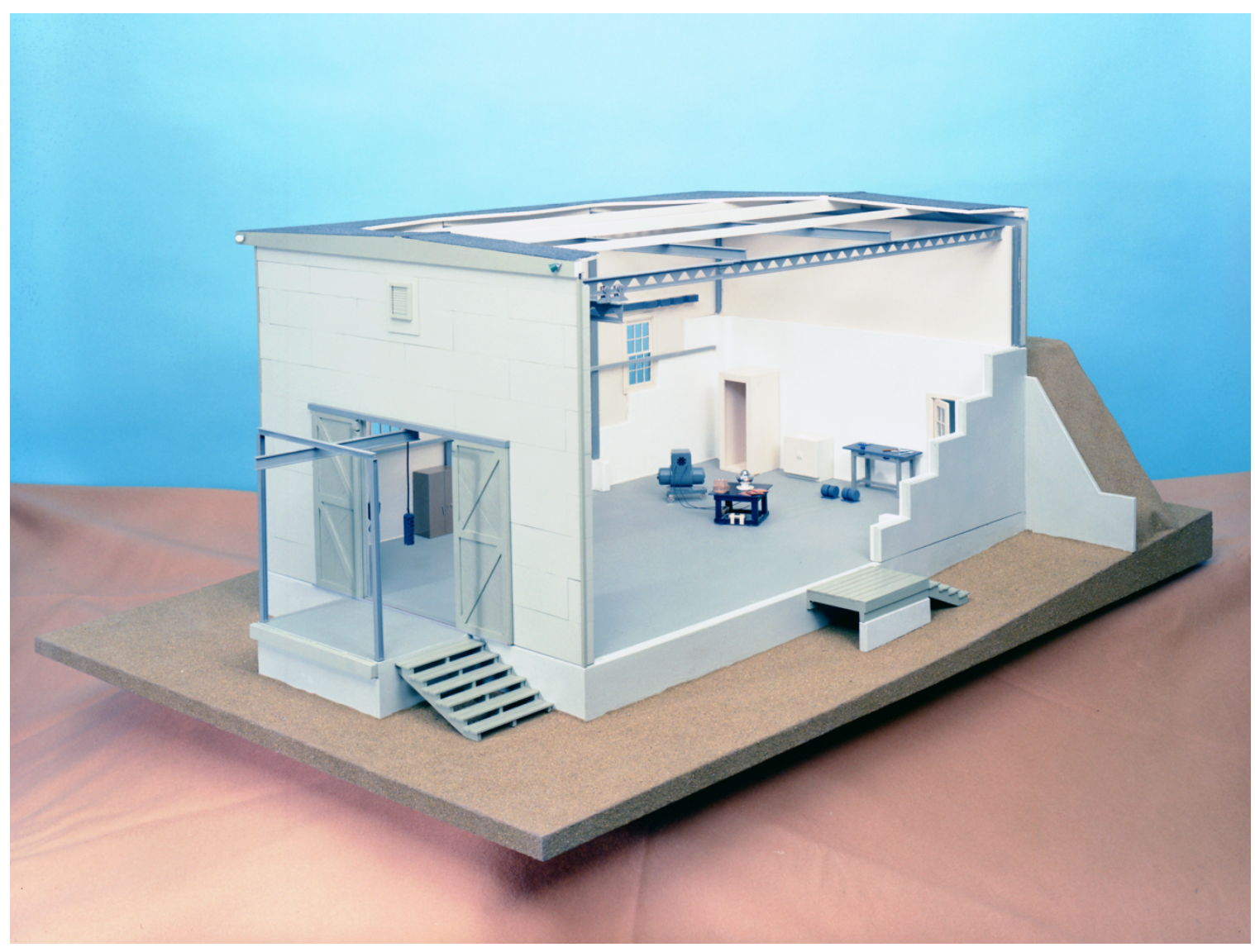

\section{Slotin Accident Building}

Second of Los Alamos criticality accidents - physicist Louis Slotin mortally injured in May 1946. 


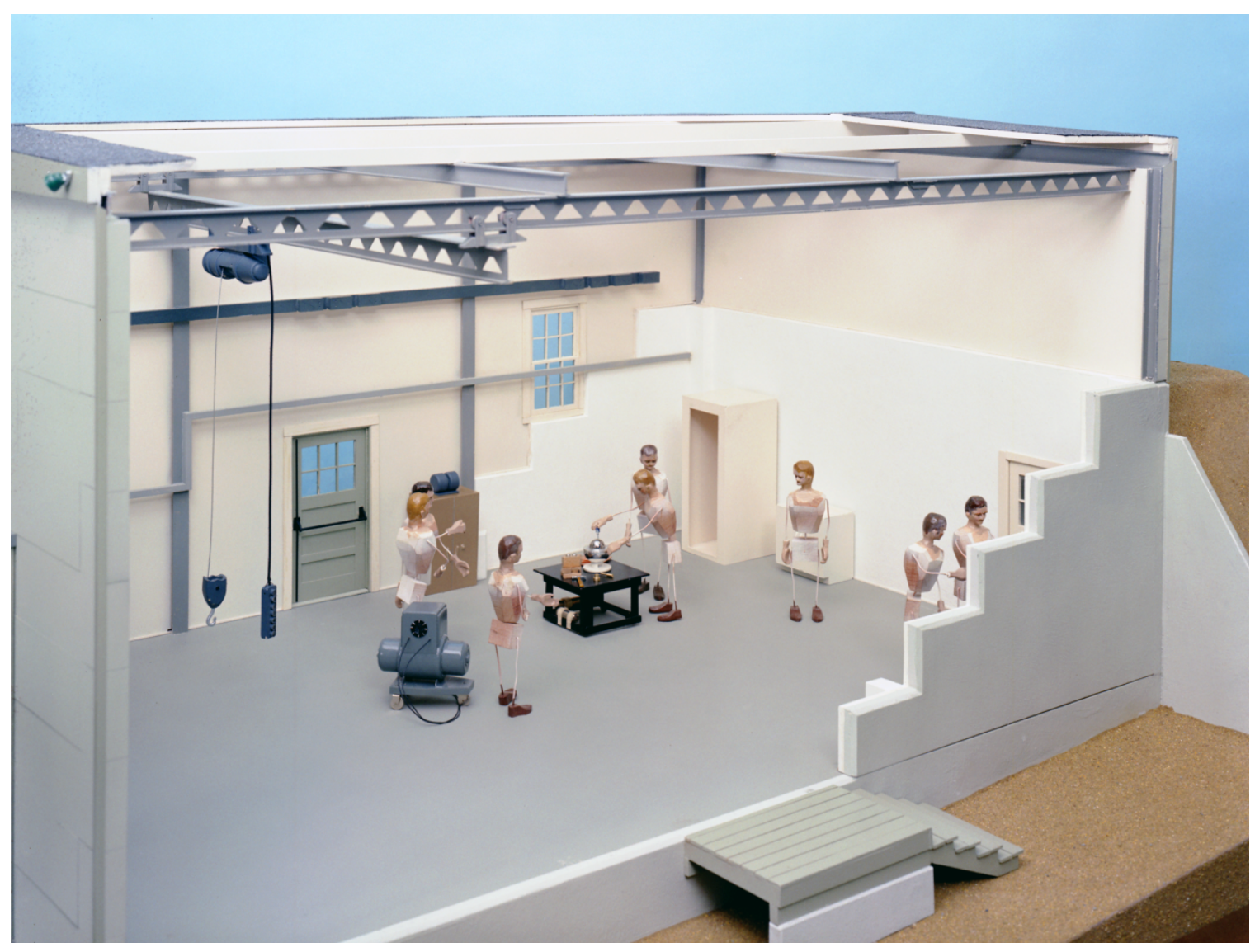

\section{Slotin Accident Recreation}

Everyone in the room, except Slotin, survived. 


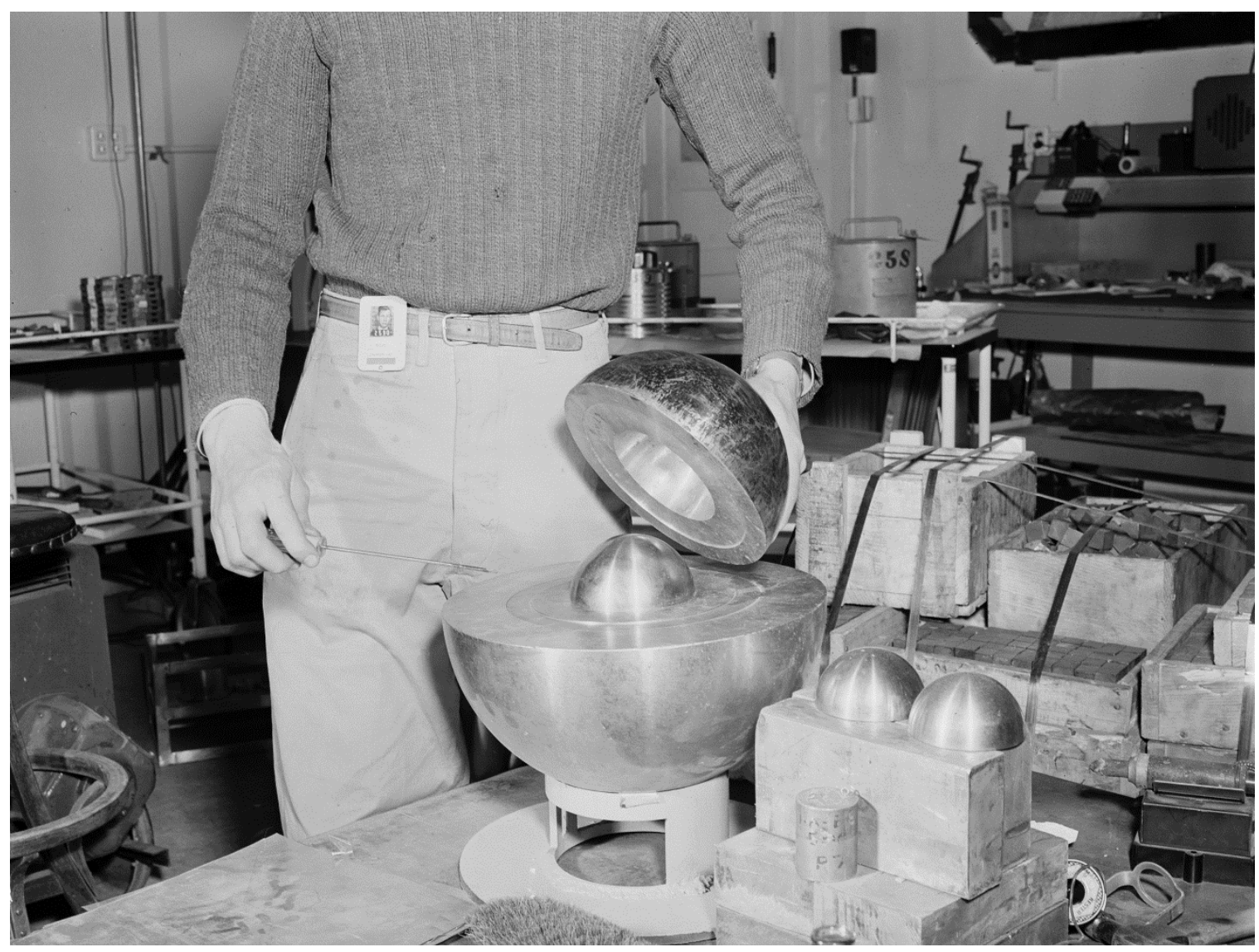

Slotin Accident Recreation

Accident reconstruction in 1946. 


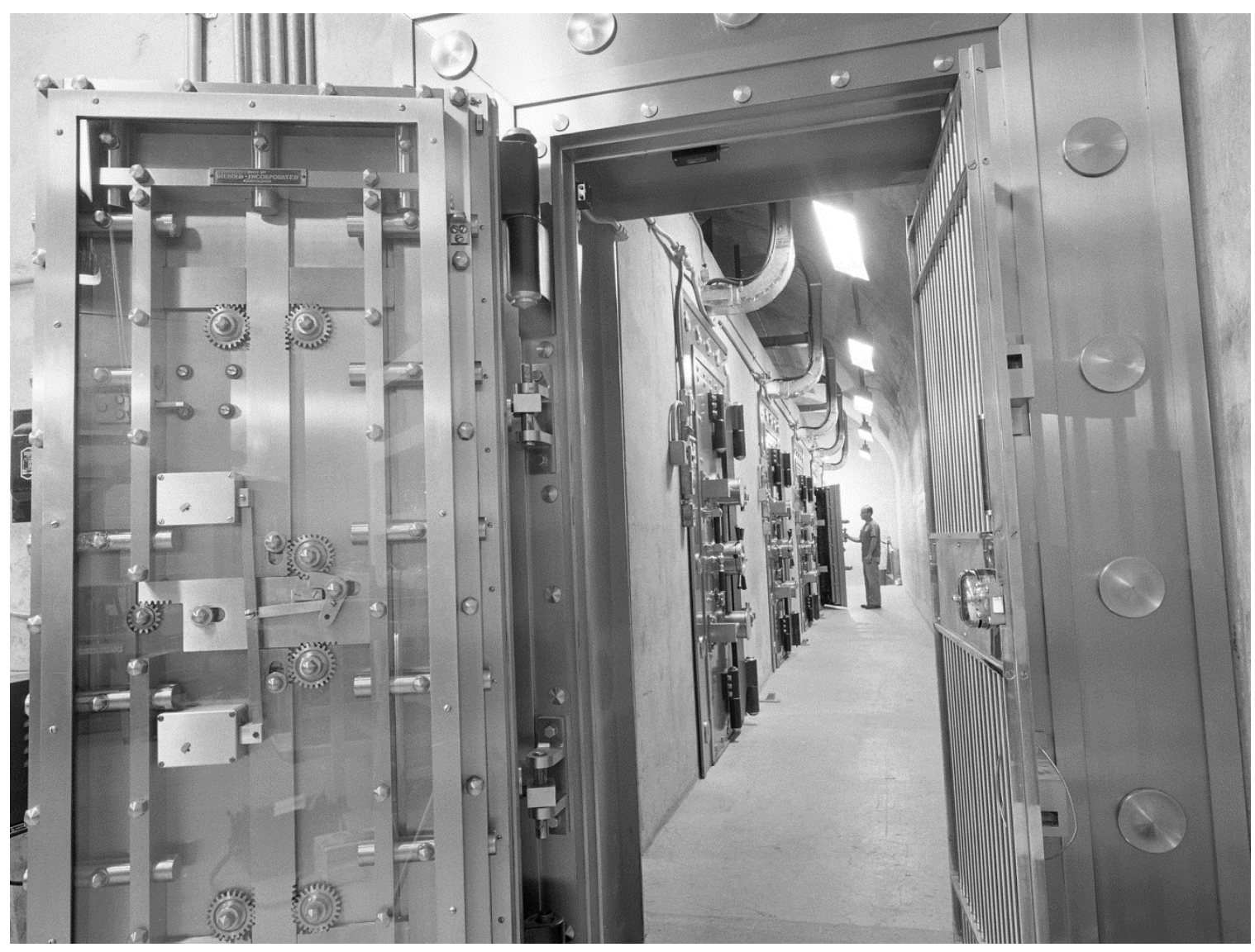

\section{Storage Vaults}

Bank vaults used to store weapon components during the 1950s. 


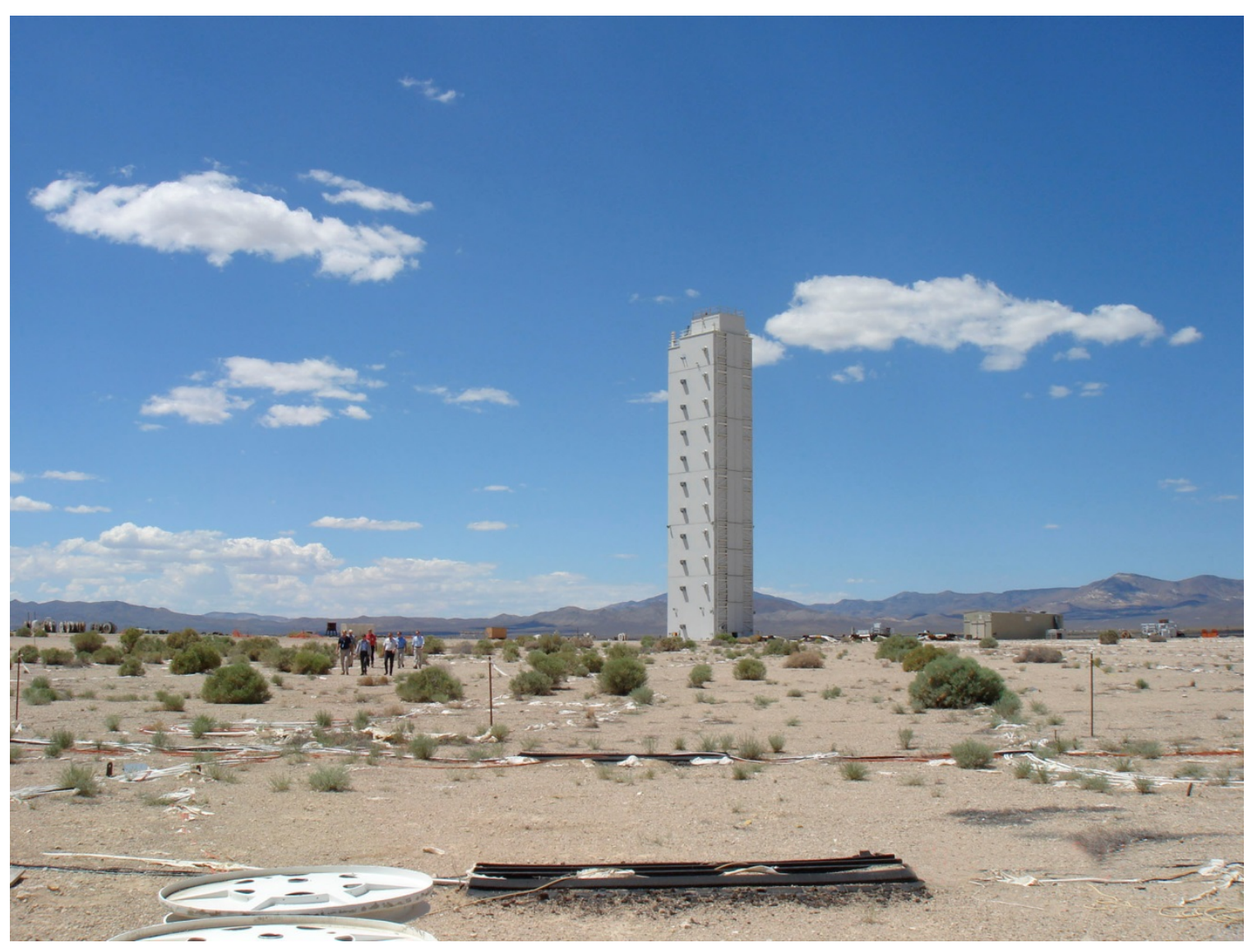

\section{Icecap Tower}

One of three towers still standing at the Nevada Test Site. 


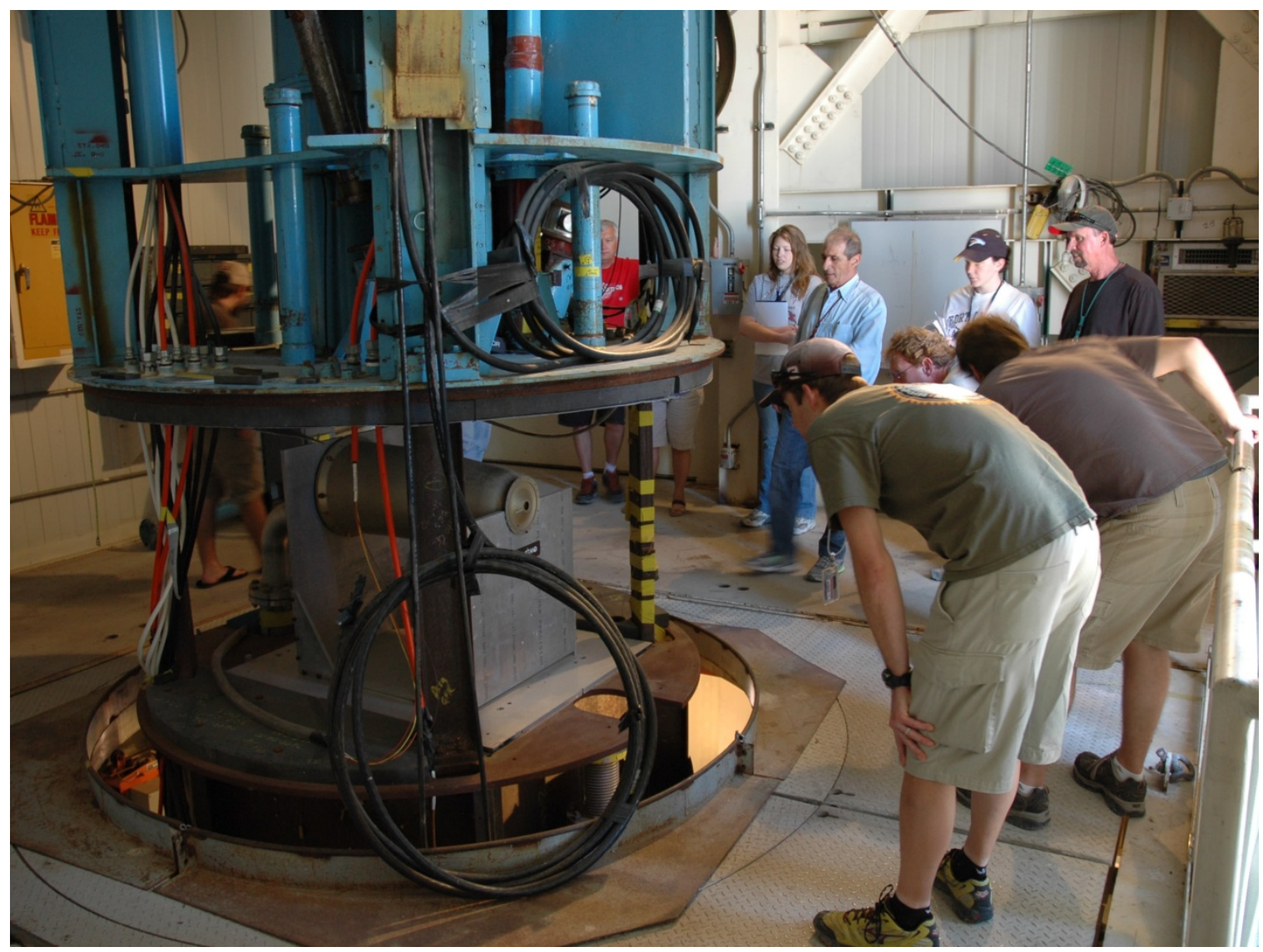

Test Rack

Bottom of rack inside the Icecap tower. 


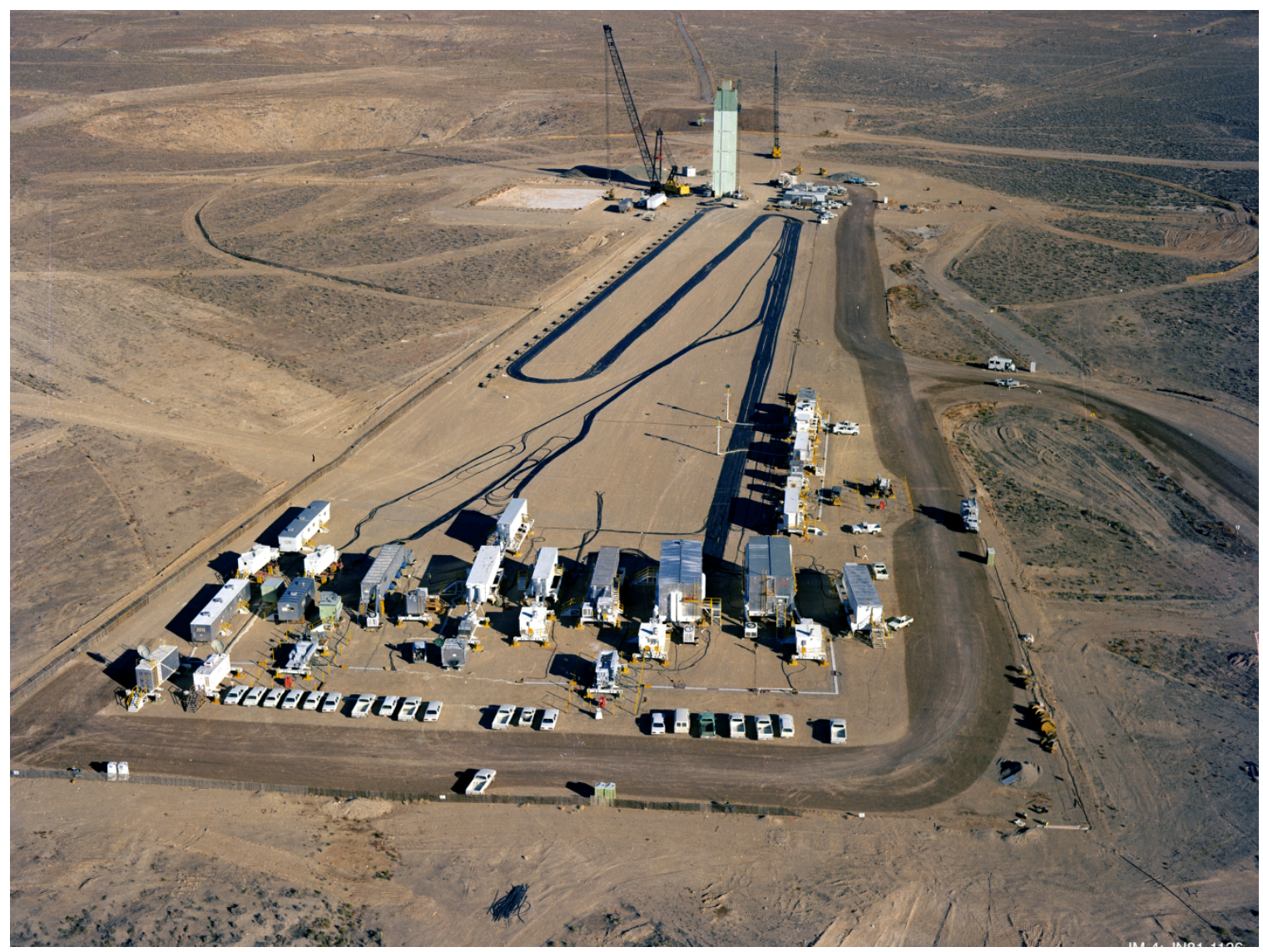

\section{Rousanne Nuclear Tests}

Typical setup for an underground nuclear test. 


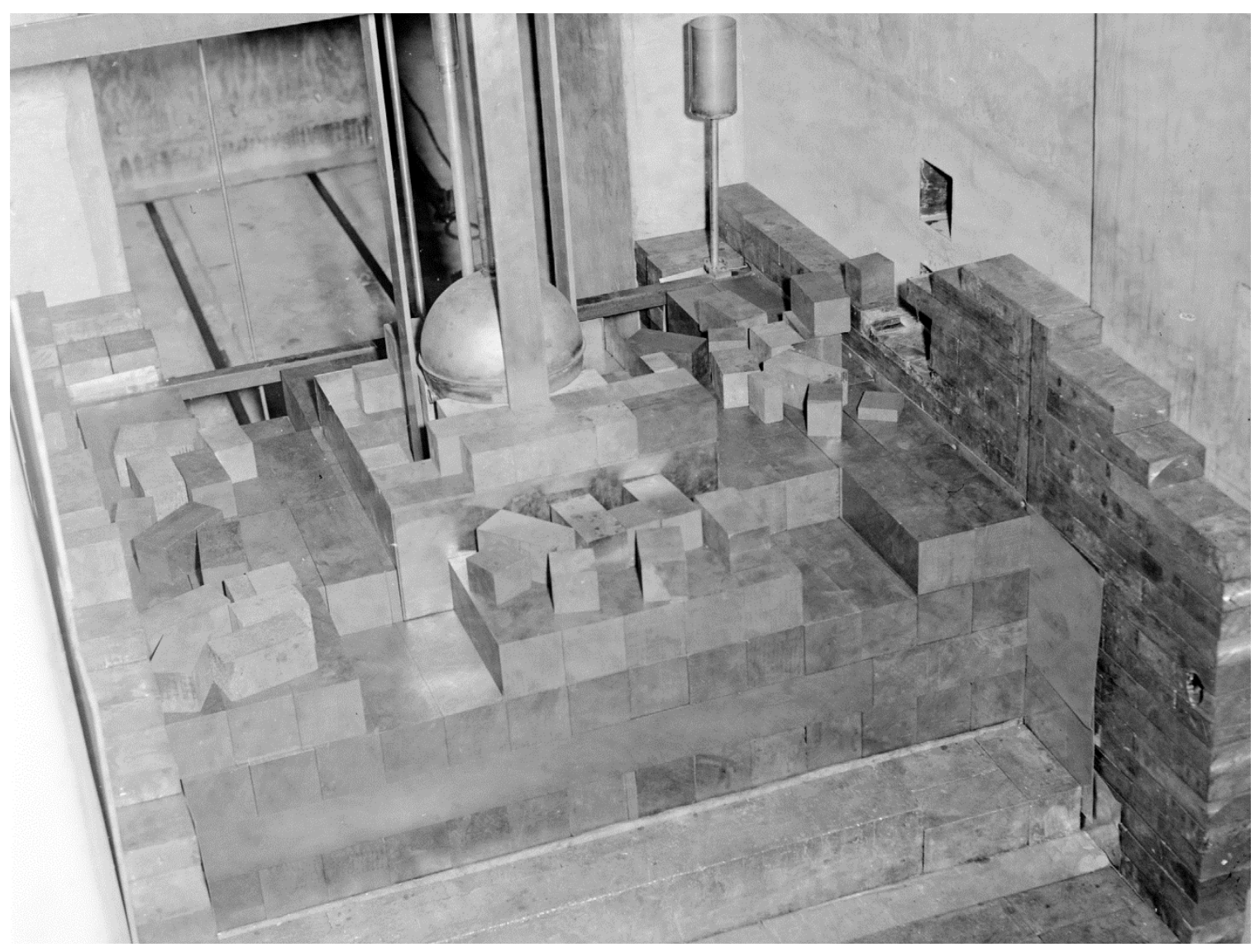

\section{Water Boiler}

Earliest reactor at Los Alamos - the third ever to go critical. Used to determine critical mass of ${ }^{235} \mathrm{U}$ for Little Boy. Later incarnations used for research. 


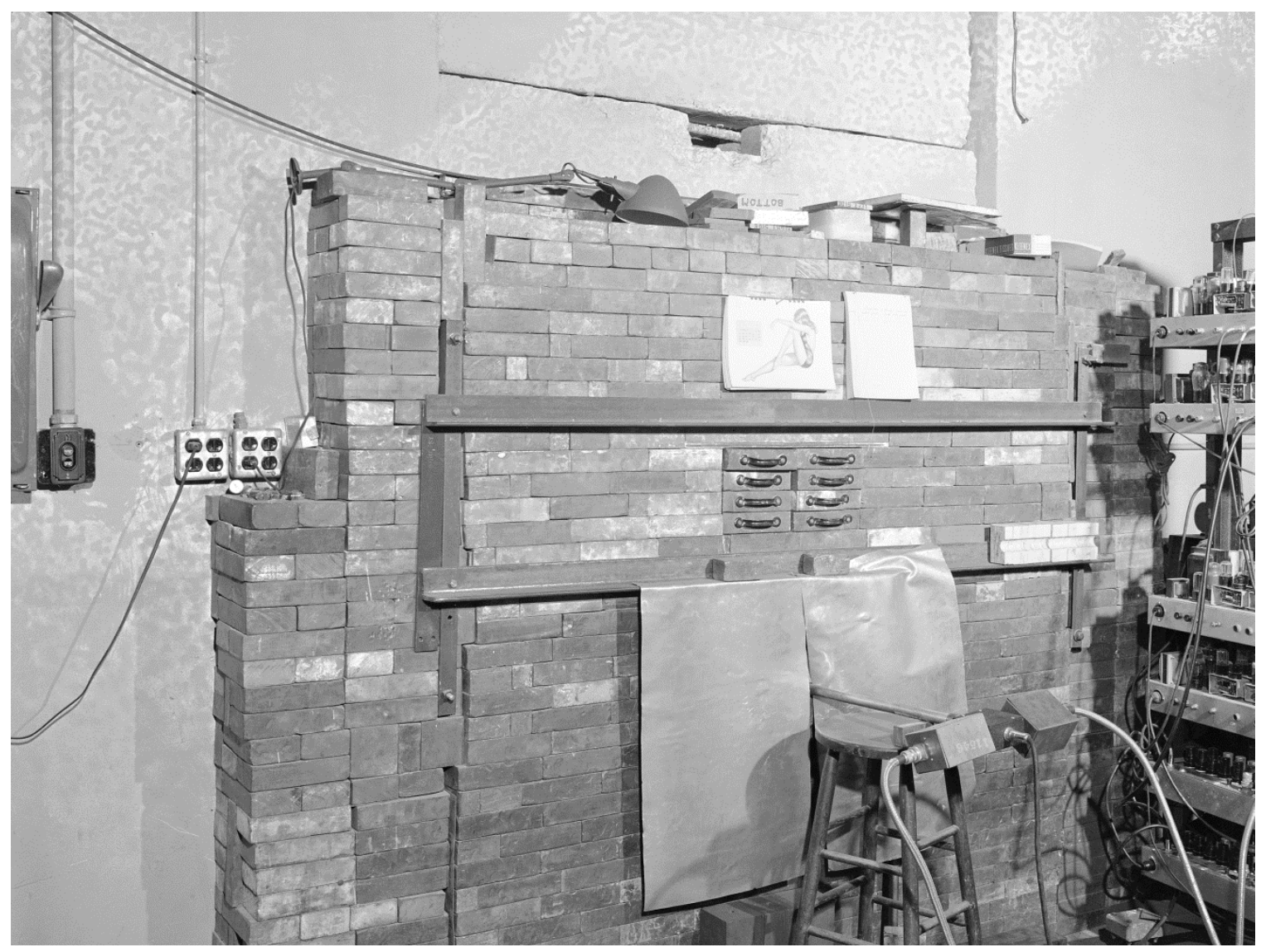

\section{Water Boiler}

Water Boiler's shielding. 


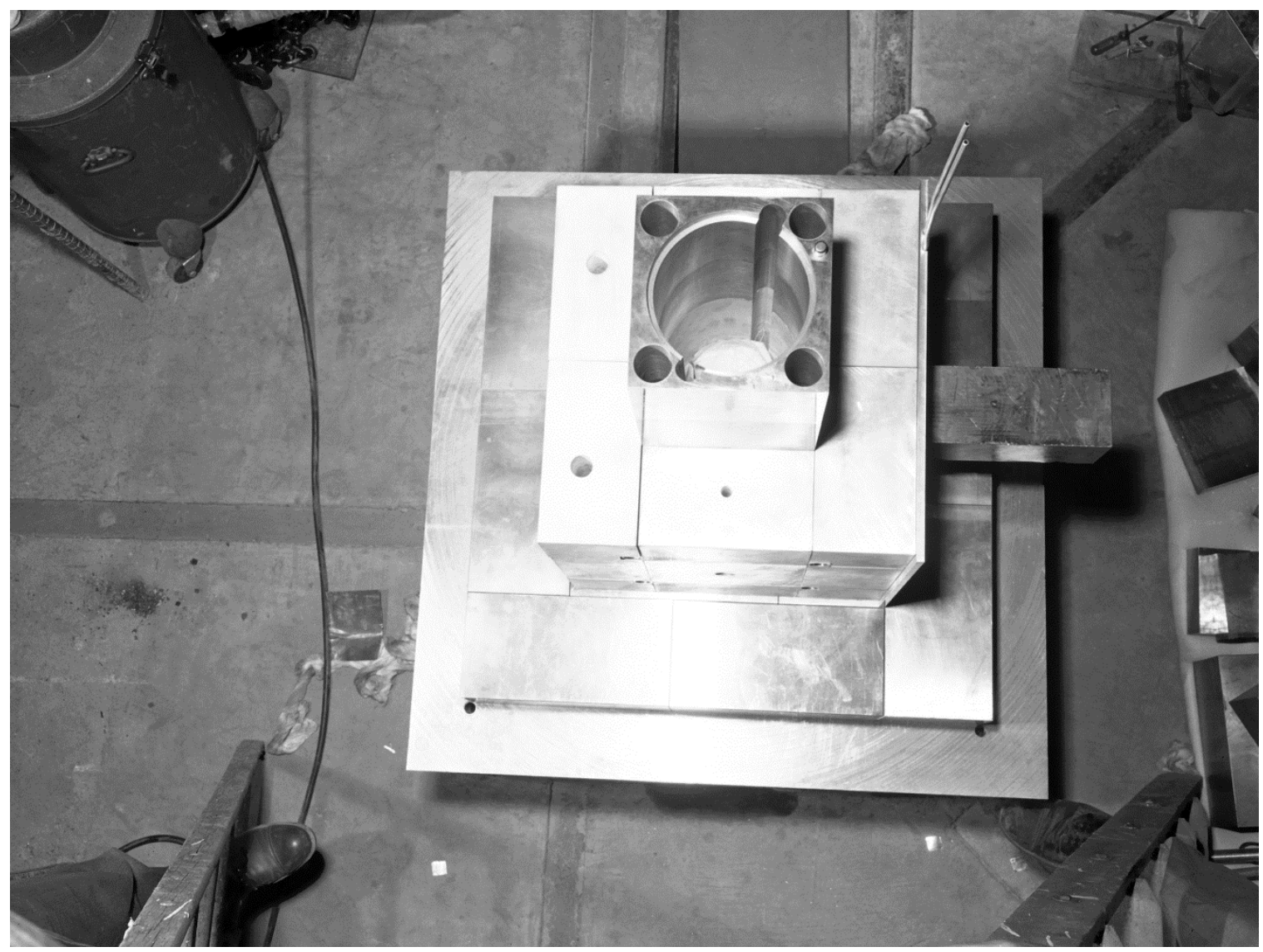

\section{Clementine}

Fast reactor that used Pu. Name is from the song "My Darling Clementine." 


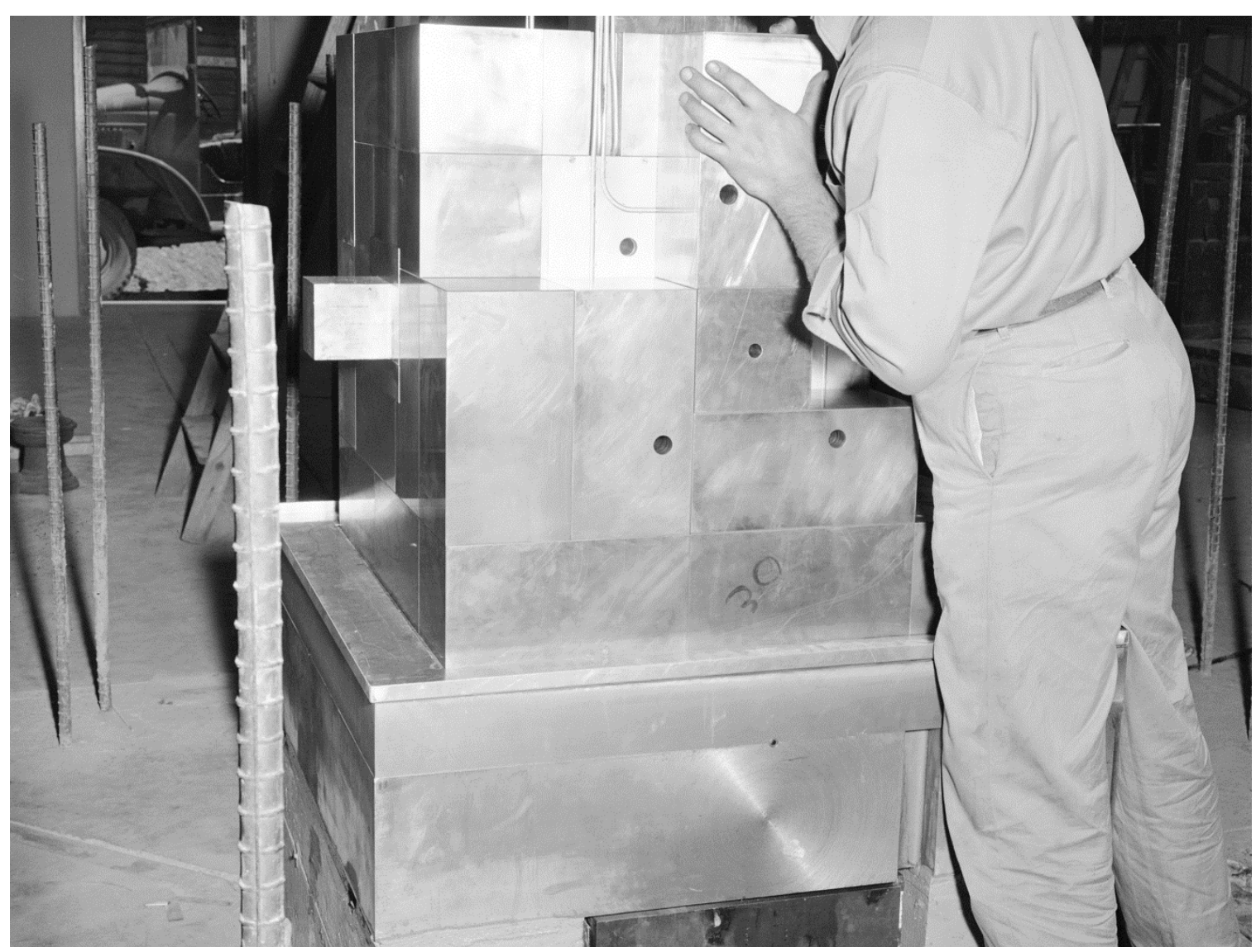

Clementine Reactor 


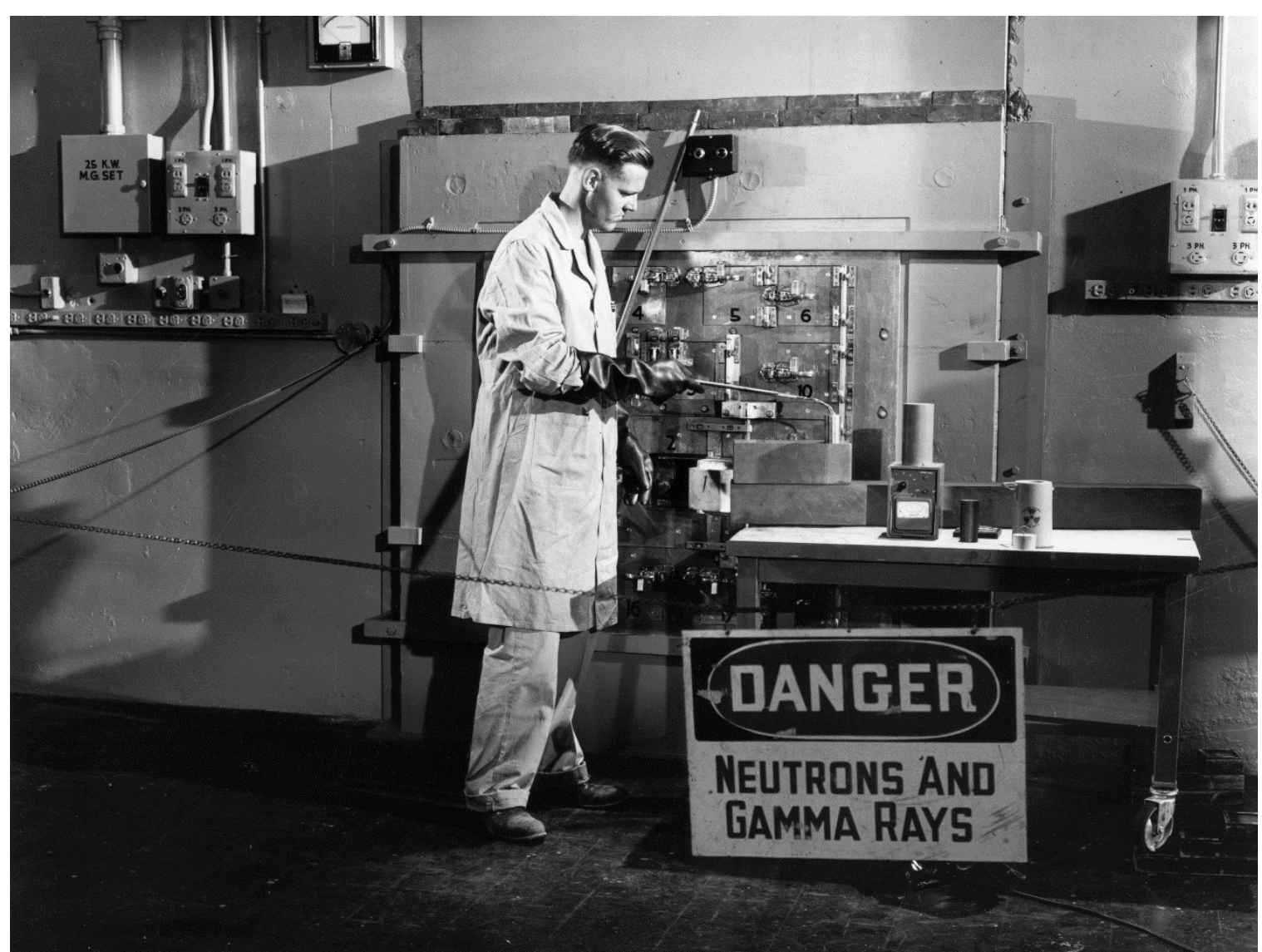

Omega West Reactor 


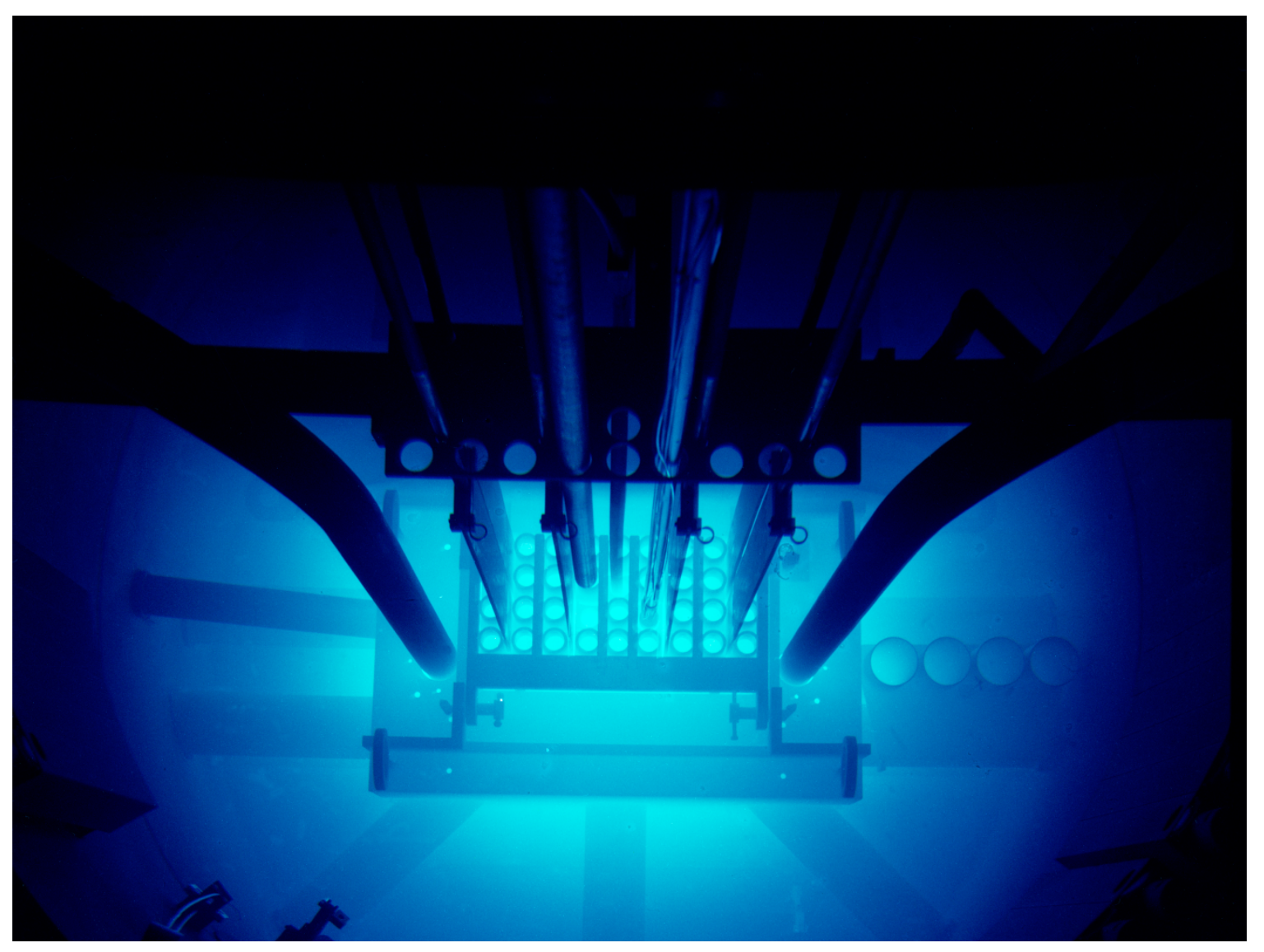

\section{Omega Reactor}




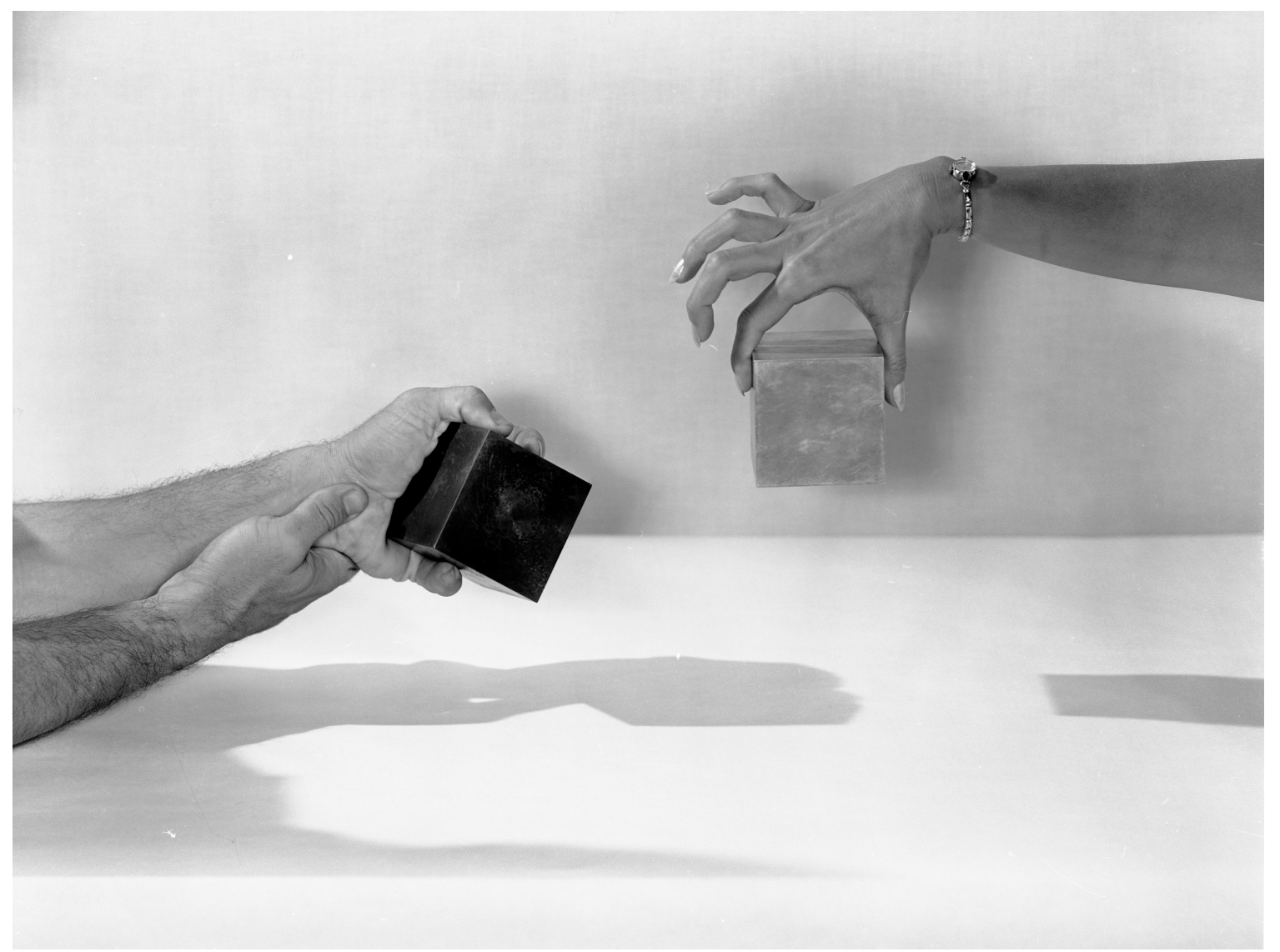

${ }^{238} \mathrm{U}$ Cubes? 